\title{
Encouraging use of subordination in children's narratives: a classroom-based priming study
}

Article

Accepted Version

Hesketh, A., Serratrice, L. and Ashworth, R. (2016)

Encouraging use of subordination in children's narratives: a classroom-based priming study. Language Learning and Development, 12 (4). pp. 413-428. ISSN 1547-3341 doi: https://doi.org/10.1080/15475441.2016.1162721 Available at https://centaur.reading.ac.uk/64583/

It is advisable to refer to the publisher's version if you intend to cite from the work. See Guidance on citing.

To link to this article DOI: http://dx.doi.org/10.1080/15475441.2016.1162721

Publisher: Routledge

All outputs in CentAUR are protected by Intellectual Property Rights law, including copyright law. Copyright and IPR is retained by the creators or other copyright holders. Terms and conditions for use of this material are defined in the End User Agreement.

www.reading.ac.uk/centaur 
Central Archive at the University of Reading

Reading's research outputs online 
Encouraging use of subordination in children's narratives: a classroom-based

$$
\text { priming study }
$$

Anne Hesketh, Ludovica Serratrice and Rachel Ashworth

School of Psychological Sciences, The University of Manchester, UK

\section{Corresponding author:}

Dr Anne Hesketh

SPS, Ellen Wilkinson Building

The University of Manchester

Oxford Road

Manchester M13 9PL

UK

anne.hesketh@manchester.ac.uk

Tel. 01612753375 
Abstract

This study investigated the long-term effect of classroom-based input manipulation on children's use of subordination in a story re-telling task; it also explored the role of receptive vocabulary skills and expressive grammatical abilities in predicting the likelihood of priming.

During a two-week priming phase, forty-seven monolingual English-speaking five-year-olds heard 10 stories, one a day, that either contained a high proportion of subordinate clauses (subordination condition) or a high proportion of coordinate clauses (coordination condition). Post-intervention, there was a significant group difference in likelihood of subordinate use which persisted ten weeks after the priming. Neither expressive grammatical nor receptive vocabulary skills were positively correlated with the likelihood of subordinate use.

These findings show that input manipulation can have a facilitative effect on the use of complex syntax over several weeks in a realistic communicative task. 


\section{Introduction}

It is widely accepted that children's language development is strongly influenced by their linguistic environment and that the amount, style and variety of the language directed to them affect both their lexical and syntactic development. Children from linguistically rich backgrounds have larger expressive vocabularies (Hoff, 2003), produce and/or comprehend more complex utterances, and use a wider range of syntactic constructions (Huttenlocher, Vasilyeva, Cymerman, \& Levine, 2002; Huttenlocher, Waterfall, Vasilyeva, Vevea, \& Hedges, 2010; Vasilyeva, Waterfall, \& Huttenlocher, 2008). One important measure of syntactic complexity is the presence of cohesive devices, i.e. connectives such as and, before, after, because, if, that link clauses and express the relationship between events in terms of addition, chronology, causality or counterfactuality.

Children's language typically develops in league with their cognitive development, allowing them to express more complicated relationships between events or states as they come to conceptualise them. At first, children may simply juxtapose clauses to indicate a relationship between them, without the use of an overt conjunction (Diessel, 2004, p. 150) before the appearance of and, which occurs as early as two and a half years and may gradually be extended in use to express temporal sequence and even causal relations (Peterson \& McCabe, 1987; Tager-Flusberg, 1989, p155-156). Literature reviewed by Diessel (2004) universally confirms and as the first conjunction, with the typical developmental order for further connectives being because, so, but and when (with if, or, while, since, after and before appearing later). Note the interleaving in emergence of 
what are traditionally thought of as coordinating ( $a n d, s o, b u t)$ and subordinating (because, when) conjunctions; indeed Diessel (2004) disputes this distinction, arguing that some adverbial subordinates are adjoined to rather than embedded in another clause, and function in a very similar way to coordinated clauses. Consider it was raining so he got wet alongside he got wet because it was raining. 'So' is generally described in this form as a coordinator, but the relationship described in the two utterances is conceptually and grammatically very similar. The most important step up may be from 'and' which simply juxtaposes clauses. Thus the later coordinators as well as the adverbial causal and temporal conjunctions, represent an integration of adjoining clauses in increasingly sophisticated ways. By the age of five, children use a range of connectives to link clauses (Spooren \& Sanders, 2008) however, there is a large and subtle range of subordinating conjunctions, and children as old as nine and ten still perform better on the use of coordination than subordination overall (Crosson, Lesaux, \& Martiniello, 2008).

The use of connectivity, particularly subordination, is crucial in making a text cohesive, allowing speakers to relate events in more effective, clear and concise ways than a series of single-clause or and-coordinated statements. During the school years, the ability to use syntactic subordination to understand and express complex ideas and concepts becomes increasingly important, and complex sentence grammar is an explicit target for both spoken and written English in the UK National Curriculum (Department for Education, 2011b). A better understanding of what supports and predicts children's use of syntactic subordination in classroom-based activities was therefore the aim of this study. 
The effects of input manipulation on language production

A vast body of research in the psycholinguistic literature has shown that one of the significant predictors of the syntactic choice of a given construction is its recent use in previous discourse. In a seminal study, Bock (1986) showed that adult speakers in a picture description paradigm were more likely to produce a passive such as "the girl was kissed by the boy" after hearing and repeating another passive, than after repeating an active, such as "the boy kissed the girl". Since then, the effects of structural priming in adults have been demonstrated for other syntactic structures, without the need for repetition (Savage, Lieven, Theakston, \& Tomasello, 2003), across different tasks (Kaschak, 2007) and between spoken and written modalities (Cleland \& Pickering, 2006). Experimental studies have shown that children too can be primed to produce a range of syntactic constructions such as passives (Bencini \& Valian, 2008; Messenger, Branigan, \& McLean, 2011), double object and prepositional object datives (Rowland, Chang, Ambridge, Pine, \& Lieven 2012; Shimpi, Gámez, Huttenlocher, \& Vasilyeva 2007;), and indirect speech clauses (Serratrice, Hesketh, \& Ashworth, 2015). Structural priming has been shown clearly in children as young as four years (Savage, Lieven, Theakston, \& Tomasello 2003) and, less strongly, in three year olds (Shimpi et al., 2007; Thothathiri \& Snedeker, 2008). It is interesting to note that the effects of priming are not always restricted to the intended target: in Vasilyeva and Waterfall's (2012) study, priming of the passive in five- and six-year-old Russian children resulted in the increased use of non-passive constructions that served the same function of profiling the patient, i.e. altered Word-Order construction and the Impersonal 
Active . They argue that what is primed is not just a formal structure, but a way of interpreting and describing a situation.

Research evidence is increasing on the priming of complex syntax specifically, with some success. Branigan, McLean and Jones (2005) successfully primed relative clauses in 3-4 year old children however only the noun phrase plus relative was required (e.g a cat that is blue) and not a longer utterance containing the relative clause embedded within it. Marinellie (2006) found that children aged seven to eight years with specific language impairment (SLI) could be primed for adverbial subordinate clauses but not relative clauses, even though the latter were occasionally used spontaneously. In contrast, Foltz, Thiele, Kahsnitz, and Stenneken (2015) and Garraffa, Coco, and Branigan (2015) both demonstrated priming of subject relative clauses in children with SLI, aged four and five years (German and Italian -speaking respectively), although in the latter study they made less cumulative gain from repeated exposure than typically developing peers. As Kidd (2102) points out, participants' existing command of the target structure, and their linguistic capacity may both be important factors in priming success. Klein, Moses, and Jean-Baptiste (2010) acknowledge the elicitation of complex sentences as difficult, needing a situation that requires an explanation of the relationship between two events. However, we do know that children's use of subordination can be influenced by their language environment outside the lab, as there is evidence that the complexity of talk from carers and teachers can affect children's syntactic growth, including the use of complex multi-clause utterances (Gamez \& Levine, 2012; Huttenlocher et al., 2002; Huttenlocher et al., 2010). 
Most of the structural priming research has demonstrated its effects over a short time period (often within a few utterances) and in constrained laboratory tasks (frequently picture description). However, there is increasing evidence that the effects of priming can be longer-lasting and occur in less constrained situations. Duration of priming has been demonstrated to last between a week (Kaschak, Kutta, \& Schatschneider 2011) and a month (Savage, Lieven, Theakston, \& Tomasello, 2006), depending on the nature of the prime and the required response. Beyond the laboratory, studies have shown effects of priming in more dialogue- or narrative-based naturalistic situations, for example Gries (2005) in naturalistic corpus data. Alignment in spoken dialogue is the tendency of speakers to make similar choices at any language level, from phonetic to pragmatic. Branigan, Pickering, McLean and Cleland (2007) showed structural alignment in conversations (affecting both direct addressees and 'side participants', to different degrees), and Reitter and Moore (2014), in dialogues with a collaborative purpose.

\section{Theoretical explanations of structural priming}

Structural priming has been attributed by some to residual activation of the syntactic structure representations common to comprehension and production (Pickering \& Branigan, 1999), which significantly increases the chances in the short-term that the same structures will be accessed in subsequent processing. Alternatively, the priming effect has been explained as a form of implicit learning (Chang, Dell, Bock, \& Griffin, 2000), acknowledging findings that priming can persist over time and in the absence of lexical overlap (Bock \& Griffin, 2000). 
Increasing evidence for the longer-term effect of priming suggests that residual activation alone is an insufficient explanation but, more recently, a number of authors have argued that both residual activation and implicit learning are implicated in structural priming, and that these accounts are to be considered as complementary explanations of language learning and change (e.g. Ferreira \& Bock, 2006; Pickering \& Ferreira, 2008). The retrieval and processing of a syntactic structure leads to a boost in its activation which will have a short-term priming effect, subject to decay. However, the boost never completely returns to baseline, and repeated processing of a structure results in incremental increases in its resting activation level; a form of implicit learning (Jaeger \& Snider, 2013).

With the advent of more inclusive theoretical explanations has come a broader consideration of the influences on speakers' choices of syntactic structure. Kaschak et al. (2011) propose that speakers develop local norms, or expectations of the appropriate style for a situation, and will remember and return to that style under similar conditions of task or interlocutor. Kaschak et al.'s (2011) study involved young adults in a written sentence completion task which manipulated their bias towards either a double object or prepositional object construction. Their everyday language experience over the intervening period would tend to return them to their baseline preference, but participants demonstrated the experimentally induced bias again on return to a second testing session a week later. This broad situational influence can be related to the narrower conversational and collaborative alignments described by Branigan et al. (2007) and Reitter and Moore (2014), reiterating the idea of context-based expectations which (in the case of adults at least) may not change language 
capacity but do affect language use.

In language-competent adults, the adaptation to context may be rapid. Fine, Jaeger, Farmer, and Qian (2013) found that adults, in a comprehension task containing ambiguous or 'garden-path' stimuli, rapidly learned to expect the ambiguous form, i.e. they adapted to the local syntactic probabilities of a novel environment. They suggest that the element of surprisal in the unexpected construction may itself have been important, leading to more rapid adaptation on the part of the listeners. Jaeger and Snider (2013) also found the surprisal effect in production: the more unexpected the prime construction (in relation to previous language experience), the more likely it was to be repeated. Priming surprisal effects have also recently been demonstrated in children as young as three to four years by Peter, Chang, Pine, Blything, and Rowland (2015).

Pickering and Ferreira (2008), noting the growing evidence of priming across linguistic levels, tasks and timescales, recommended that further research should investigate the application of priming in language learning, including education, bilingual acquisition and treatment of language disorder. A notable example is that of Vasilyeva et al. (2006) who demonstrated week-long effects of priming children's use of the passive in a more naturalistic setting, embedding the target constructions in a series of stories in a classroom situation. Similarly, Ryokai, Vaucelle, and Cassell (2003) used a virtual animated child character 'Sam' to take turns with five-year-old children in telling stories about a toy figure and a magic castle. Sam modeled direct speech, temporal and spatial expressions and relative clauses, the first three of which increased significantly in the 
children's own stories as they took turns. The effect was also seen when two children interacted with the character at the same time. Stories appear to have particular potential for young children as in Klein et al.'s (2010) comparison of procedures, ranging from free play to story re-telling: the more constrained retell task was the most effective in eliciting multi-clause sentences in children aged $4 ; 7$.

\section{Individual differences in response to priming}

Although significant effects of priming have been reported in numerous studies, group differences may mask a degree of individual variation, with the priming effect being driven by a small number of tokens and a small number of participants. In a recent study Kidd (2012) did find considerable individual differences in the likelihood of priming in 122 children between four and six years. Larger receptive vocabularies and better receptive grammar and nonverbal reasoning skills were positively correlated with children's likelihood of being primed to use a passive. Serratrice et al. (2015) also found that expressive grammatical skills were positively correlated with the likelihood of priming in a group of 42 children between five and six years. These findings suggest that children's own linguistic skills should predict whether they will be more or less likely to take up the syntactic construction modeled in the prime.

To sum up, there is substantial evidence that, by four years of age, children can be primed to produce constructions they do not regularly use. Priming of less frequent structures recalibrates children's probabilistic expectations of encountering such structures, and it is likely to facilitate the entrenchment of 
their mental representation. Most of the existing literature looks at priming of single clause utterances over the short-term, and in a lab-based constrained experimental setting, thus is distant from communicative language use and development. To enhance our understanding of how priming affects language learning and language use, we need to investigate its effects over longer periods of time and larger units of language (Kaschak et al., 2011), while recent research points to the value of story-telling, and the use of multi-person dialogues in extending children's syntactic repertoire (Lever \& Sénéchal, 2011). In this study we dealt with some of the limitations of previous research. Firstly, we took the priming methodology out of the lab and investigated whether children's language use can be affected by input manipulation in the context of everyday classroom-based language and literacy activities. Secondly, we explicitly targeted the effects of input manipulation on children's use of multi-clause utterances. Our third aim was to test the effects of priming in a more meaningful communicative task; instead of picture-description we embedded the constructions of interest in a story telling activity. A fourth aim was to contribute to the evidence on longer-term effects of priming; we tested children one week and 10 weeks after the priming phase. Finally, we investigated the relationship between priming and language skills; we measured children's receptive vocabulary and expressive grammar and correlated them with the results on the priming task at two time points.

The study was designed to answer the following three questions: 
1) Is a two-week daily exposure to stories containing a high concentration of subordinate clauses effective in promoting children's own use of subordination in a subsequent story-retelling task?

2) Are the effects of targeted exposure to subordination persistent over time? 3) Is there a positive correlation between children's receptive vocabulary skills and/or expressive grammatical skills and the likelihood of producing subordinate clauses after a priming phase?

\section{Methods}

\section{Participants}

Forty-nine monolingual English-speaking children were recruited from a primary school in the North West of England (mean age $=5 ; 11$, age range $=5 ; 5$ 6;5 ); two children were eventually excluded due to absence in one of the posttests. The percentage of children on free school meals in the school, an indicator of social deprivation, was $15 \%$, close to the then national average of $17 \%$ (Department for Education, 2011a). The children were in two classes that were randomly assigned to one of two priming conditions: Subordinate Clauses condition (SUB, $\mathrm{N}=24$ ) or Coordinate Clauses condition (COORD, $\mathrm{N}=23$ ).

\section{Materials}

Before the priming phase children were individually assessed by a trained researcher for receptive vocabulary (British Picture Vocabulary Scale, BPVS-3; Dunn, Dunn, Styles, \& Sewell, 2009) and expressive language abilities (Formulated Sentences sub-test of the Clinical Evaluation of Language Fundamentals, CELF-4 UK; Semel, Wiig, \& Secord, 2006). In the Formulated 
Sentences subtest the child is asked to produce a sentence about a picture, containing a given word. It thus assesses the ability to formulate semantically and grammatically correct sentences of increasing complexity.

The assessment and the priming materials consisted of thirteen different narratives loosely inspired by children's books or traditional stories. Three were used for the assessment sessions, ten for the intervention, i.e. children heard each story only once. They were produced as PowerPoint presentations with ClipArt pictures or as videos using toy figurines and simple props, and accompanied by a digital recording of the story narrated by one of four different speakers. The assessment stories were each read by a different adult female narrator. The stories were, on average, 31 sentences long and contained 20 tokens of the target construction (i.e. either a coordinate or a subordinate clause). Each story had two versions; the SUB condition contained 20 examples of temporal and causal subordinate clauses, which were replaced with coordinated clauses (always using and) in the COORD condition (see Appendix A). Apart from this manipulation the stories were identical in the two versions. The most frequent subordinating conjunctions (and their number of appearances across all 13 stories) were because (97), when (54), after (10) and before (9). In order to ensure that the stories sounded natural, they included some other examples of clausal coordination (most commonly but and then) and subordination, though no other causal or temporal subordinate clauses.

The story in the pre-test assessment for all children was identical in structure to the COORD example in Appendix A. It did not contain any temporal or causal 
subordinate clauses as we wanted to establish a pre-priming baseline for children's use of subordination; in essence we wanted to know whether children would be likely to use any subordinate clauses in the re-telling of a story that did not contain any. In the two post-tests all the children were exposed to stories containing 20 tokens of subordinates.

\section{Procedure}

Children were assessed individually on three separate occasions: before the start of the priming phase (pre-test), one week after the end of priming (post-test1), and ten weeks after the end of priming (post-test2). One researcher assessed children in the pre-test and delivered the two-week priming intervention; a different researcher, blind to group allocation, carried out the post-tests. Language measures were collected during the pre-test assessment. Children's responses on the CELF-4 UK were audio-recorded, transcribed and scored later by the same researcher. Approximately $20 \%$ of answers were independently coded by the first author, a qualified speech and language therapist. Agreement was 95\%; any disagreements were resolved between the two coders.

During the pre-test assessment session the children sat at a table facing a 15" laptop where they watched and listened to a short story while the experimenter worked in another part of the room. The experimenter then returned and asked the child to tell the story in their own words as they watched the video together with the sound off. During the re-telling of the story the experimenter gave general encouragement but did not cue the child explicitly in the use of any content or syntactic constructions. Children may reduce to the gist of a story 
where they feel that a listener already knows the content (Geva \& Olson, 1983): we tried to circumvent this by setting up a situation where the adult appeared not to know the story, thereby encouraging our participants to recount it as fully as they could. Children's narratives were digitally recorded for later transcription and coding.

The priming phase was delivered as a group intervention to a whole class of children, randomly allocated to either the SUB or the COORD condition. Children were told that they were going to watch a story and were introduced to a puppet, Fred, a lazy frog who was likely to fall asleep and then wake up wanting to know what had happened. The class watched and listened to the presentations projected on a big screen while the researcher narrated the story and Fred fell asleep. In the SUB condition, children were shown a version of the story using temporal and causal subordinating conjunctions (e.g. Princess Eliza was crying because she wanted a pet). In the 'COORD' condition, children watched the same video but the script used coordinating conjunctions (e.g. Princess Eliza wanted a pet and she was crying). At the end of the video, Fred woke up and the narrative was run again with class participation while Fred asked a number of questions. Some were purely factual, in order to encourage the children's participation (e.g. What colour was the princess's dress?). However, to further highlight the constructions of interest, the puppet interrupted the narration for 10 of the 20 target constructions and asked the children to clarify what had just been described, e.g. Fred: “So why was Princess Eliza crying?” (SUB condition). To make this task as natural as possible the experimenter left it to the children to volunteer responses and no special effort was made to ensure that everyone had 
a turn. As the answers to the questions only required one clause to be stated (e.g. Because she wanted a pet), following the children's reply the experimenter restated the answer using both clauses (e.g. Yes, Princess Eliza was crying because she wanted a pet). In each condition the children were therefore exposed to 30 instances of either subordination or coordination per story, giving a total of 300 instances over 10 days.

The two post-assessment sessions followed exactly the same procedure as the pre-test, except that the stories, for both groups, contained 20 subordinate clauses.

\section{Transcription and coding}

The children's narratives from all assessment sessions $(\mathrm{N}=141)$ were transcribed by two trained English native speakers using the CHAT system as described in the CHILDES manual (MacWhinney, 2000). All multi-clause utterances were coded as examples of coordination or subordination, relying on use of pausing, semantic coherence and conjunctions to make decisions about utterance boundaries and type of subordinate. Only utterances where the correct meaning was successfully encoded were counted as examples of subordination. All the coded utterances were checked by the second author; agreement on decisions was $90 \%$, and any disagreements were resolved by discussion between the coders.

\section{Results}

Descriptive statistics for the children's age in months, receptive vocabulary and 
expressive language scores are reported in Table 1. The means for both receptive vocabulary (BPVS) and expressive grammar (CELF FS) were within 1 SD below the mean and normally distributed. There were no significant differences between the two groups with respect to age $(t(45)=-.91, p=.37)$, receptive vocabulary scores $(t(45)=.352, p=.73)$, or expressive grammar scores $(t(45)=-1.29, p=.21)$.

Please insert Table 1 here

The effect of input manipulation in the priming phase

Table 2 reports the descriptive statistics for the use of all types of subordination and coordination at the three assessment points.

Please insert Table 2 here

At pre-test, most children already spontaneously produced some subordinate clauses (mostly because and infinitival clauses; median $=10 \%$ of the total number of utterances). Children in the COORD group produced, on average, more subordination but independent samples t-tests confirmed that the groups did not differ significantly at pre-test in number of subordinate clauses $(\mathrm{t}(45)=-1.68, \mathrm{p}=$ $.10)$.

Mixed effects logistic regression was used to model the binary outcome of subordination use; we used the glmer function in the lme4 package for Linear Mixed Effects (Bates \& Maechler, 2010) in R (version 3.1.3). Our dependent 
measure was the likelihood of producing a subordinate clause. That is, every production of coordination or subordination produced by each child was coded as a binary variable $(1=$ subordinate, $0=$ coordinate $)$. The fixed factors included in the model were: Priming Condition (Subordination, 0.5; Coordination, -0.5), Phase (Post-test1, -05; Post-test2, .05). The BPVS scores and the CELF Formulated Sentences scores were included as covariates to assess the extent to which receptive vocabulary skills and productive grammatical skills affected children's performance. Participants were included as a random factor. We started with a model including only the random factor and compared nested models using a log-likelihood Chi-square test.

There was a significant effect of Priming Condition $(\beta=0.71(\mathrm{SE}=0.17), z=4.11$, $p<.001$ ) showing that the likelihood of producing a subordinate clause was significantly higher in the SUBORD group. The effect of Phase was also significant $(\beta=0.36(\mathrm{SE}=0.16), z=2.19, p<.01)$ confirming that the likelihood of subordinate use was higher at Post-test2, but there was no significant interaction between Priming Condition and Phase $(\beta=-0.02(\mathrm{SE}=0.24), z=-0.08, p=.93)$, and no significant effect of the covariates BPVS $(\beta=-0.003(\mathrm{SE}=0.01), z=-0.26$, $p=.79)$ or CELF $(\beta=0.03$ (SE $=0.03), z=0.98, p=.32)$ on the likelihood of subordinate use.

We also conducted separate logistic mixed effects models for the data at Posttest1 and Post-test2. For both models there was a significant effect of priming condition (Post-test1: $\beta=0.67(\mathrm{SE}=0.17), z=3.93, p<.001$; Post-test2: $\beta=0.74$ $(\mathrm{SE}=0.19), z=3.81, p<.001)$, but no significant effect of BPVS (Post-test1: $\beta=-$ 
$0.003(\mathrm{SE}=0.01), z=-0.20, p=.83 ;$ Post-test2: $\beta=-0.004(\mathrm{SE}=0.01), z=-0.27$, $p=.78$ ) or CELF (Post-test1: $\beta=0.01(\mathrm{SE}=0.04), z=0.34, p=.73$; Post-test2: $\beta=0.06(\mathrm{SE}=0.04), z=1.34, p=.17)$.

Whereas the above data focuses on likelihood of subordinate use, we also explored patterns of use of both subordination AND coordination structures in the two groups. Appendix B provides Posttest 1 narrative extracts from one SUB and one COORD group child, showing that both children use both mechanisms for linking clauses, as indeed they did before intervention. Figure 1 focuses just on structures which were specifically primed ('and', and the temporal/causal conjunctions only) and shows the mean use for the two groups at all time points. The mean numbers are lower than in table 2, which includes all clause linkage examples, but show even more strikingly the change in use of specific primed structures immediately after the intervention phase.

Figure 1 about here

\section{Discussion}

Lab-based research has shown that by four years of age children can be primed to produce constructions they do not regularly use. Most of this research has focused on single clause utterances in an experimental context with immediate measurement of response. In an attempt to address the more complex linguistic demands made on school-age children in an everyday setting and task, this study investigated the effects of input manipulation on children's use of subordinate clauses in a functional, classroom-based narrative activity, and measured both immediate and longer-term effect. Our results showed that post-intervention, in 
the retelling of a story, children who had been primed with frequent examples of subordination were more likely to produce subordinates in their multi-clause utterances than the children in the COORD condition. This significant difference was maintained at post-test2, ten weeks after the end of the priming phase.

These results reflect two possible separate priming influences. Firstly, the immediate effect of priming with temporal and causal subordinates in the two post-test stories. Secondly, the cumulative effect of regular exposure to particular grammatical structures during the intervention phase. All children were exposed to the same stories at each assessment point, therefore the immediate priming effects were constant across the two groups. The SUB and COORD groups are differentiated by the priming they received in the intervention phase.

Before intervention (when retelling a story which contained no temporal or causal subordination) both groups showed a statistically similar preference for the use of subordination to link clauses. After sustained exposure to the subordinate constructions in the narrative intervention, the SUB group at Posttest1 increased the amount of subordinates and the likelihood of subordination use to conjoin clauses. (see table 2). In contrast the COORD group, after sustained exposure to coordination of clauses during intervention, show a contrasting increase in both the amount and proportion of coordination use. Both the intervention and the assessment narrative are possible sources of subordination priming, as stated above, and the change from coordinate to subordinate loading from pre- to post-test may also have contributed to an 
increase in subordinate use by both groups. However, following repeated priming of subordination or coordination during two weeks of narrative intervention the two groups now show a statistically significant difference in their pattern of clause linkage.

Do our results shed light on the theoretical explanations for structural priming? Rather than a lab-based study exerting a high degree of control over the experimental context, we aimed to test the practical viability of priming in a relatively unconstrained but educationally valid activity. Nevertheless, we can attempt to fit our findings to the debates about the mechanisms of priming, beginning with the early short term activation versus implicit learning dichotomy. The nature of the assessment task and the maintenance of a priming effect over a 10-week period argue against a short-term residual activation account as proposed by Pickering and Branigan (1999). For implicit learning, Pickering and Ferreira (2008) describe the process as requiring a particular meaning relationship to be repeatedly expressed via a specific grammatical construction thereby strengthening the mappings between meaning and syntax and increasing the likelihood of the same partnership being used in similar situations. Thus we have a number of important relevant elements in our intervention: the repeated grammatical input over a two-week period, the direct (though tacit) relating of the clausal linkage to describing a particular relationship between events, and the functional motivation to use this description to tell a coherent story. Because of their persisting effect, our findings support implicit learning, but we need to consider what exactly has been learned. 
In adult studies we can assume that the participants are competent users of the syntactic structures that are primed, whereas children may either enter a priming intervention with full knowledge of the target structure or they may develop their competence during the task (Kidd, 2012). Priming appears to work beyond the very short-term when the child has developed at least a partial representation of the structure not tied to particular lexical items. If andcoordination appears by $2 ; 6$, and because and other early subordinators between 2;6-3;0, clearly our participants should be familiar with both constructions. Indeed the majority did already show some evidence of being able to use subordinate constructions, and all of them could use coordination. But young children take a while to master even the early constructions, for example McCabe and Peterson (1985) described non-causal connectivity errors on $40 \%$ of because tokens used by children aged $3 ; 6-9 ; 6$, and there are many instances of grammatical difficulty in Appendix B. Therefore, we conjecture, it is possible that our participants had achieved a level of competence with coordination which they were still developing for subordination, and that the priming had different effects in the two groups; both groups learning an expectation of a particular style of syntax, and the SUB group additionally developing syntactic competence. The priming phase appears to have affected the choice of construction in both groups, reflected in their differing patterns of subordinate and coordinate use which can still be seen 10 weeks after intervention. Whether or not some have learned new competence, our groups have learned and retained (in this situation at least) a pattern of language use. 
Recent theoretical debate has begun to consider how the activation versus implicit learning accounts may interact with other cognitive or sociolinguistic factors, to influence language choice. It has been proposed that both adults and children quite rapidly learn the statistical syntactic profile of a new situation, and adjust their syntactic expectations or production accordingly. Some accounts focus on the on-line structural alignment of specific dialogues, others on the development of norms for certain situations, and others on the surprisal effect of an unexpected syntactic pattern.

Speakers have been noted to align their syntactic structures in dialogue, particularly where they are involved in a task-focused interaction (Pickering \& Ferreira, 2008; Reitter \& Moore, 2014). However, our assessment task required no dialogic interaction therefore gave no opportunity for structural alignment within conversation. More pertinent to our study is Kaschak et al.'s (2011) proposal that speakers develop local norms, or expectations of the appropriate style for a situation, and return to that style when prompted by a similar task, environment or interlocutor. Note that the prompts have only to be similar, not necessarily identical: Kutta and Kaschak (2012) found that extrinsic factors such as a change of room or background video did not undermine priming effects in adults either in the very short term or over a week. Even though the requirements, interlocutor and physical location of our task differed between the intervention and the assessment sessions, children may have developed an expectation of a particular style of clause linkage associated with the narrative listening and retelling activity led by a visitor to the school. Our assessment format (audio-recorded story accompanied by animated powerpoint slides) did 
replicate the intervention task and may have been sufficiently similar to prompt a particular style of response.

Fine et al. (2013) and Jaeger and Snider (2013) are also interested in adaptation to a linguistic situation, but specifically the apparent increase in speed or amount of syntactic adaptation where the input differs from the listener/speaker's expectation. Both groups of children in our study will have developed local norms for the narrative re-telling task during the intervention phase. Their experience should push the COORD group towards coordination and the SUB group towards the use of subordination in their retelling. No surprisal effect would be predicted for children in the SUB group on assessment, as the Posttest 1 narrative matched the subordination loading of their intervention phase stories. Any immediate priming from the Posttest narrative would be in line with the cumulative effect of the intervention phase; there was no conflict of priming for the SUB group. In contrast, any surprisal effects would interact with the situational expectations to produce conflicting influences on children in the COORD group who had developed an expectation of a coordination pattern during the intervention but were confronted with an unexpected frequency of temporal and causal subordinates in the Posttest 1 story. This high degree of surprisal should maximize their susceptibility to priming by the syntactic environment rich in subordination. We see possible evidence of this in Figure 1: although the COORD children's use of subordinators has reduced overall (see table 2), their use specifically of causal and temporal conjunctions does peak in the Posttest1 assessment. There is no such effect at Posttest 2, which again presented a subordinate-loaded narrative 10 weeks after 
intervention ended. Without the immediately preceding emphasis on coordination, the surprisal effect may not have been strong enough to prime the specific subordinate conjunctions beyond their resting level. Note that the use of and preference for coordination is highest for the COORD group at Posttest 1 . We would argue that the cumulative priming effect of the intervention has exerted a stronger influence than the immediate priming of subordination from the Posttest1 narrative.

As well as the time elapsed since intervention, the different stories used at each assessment point may also have affected children's performance. Firstly, the two subordinate-loaded posttest narratives differed from the pre-test narrative which contained no temporal or causal subordination. This change in itself may have been responsible for some of the change in children's likelihood of subordinate use and is why we have not statistically compared pretest scores with posttest. However, it is important to note that this change in narrative characteristics was identical for all participants across both groups.

Secondly, the two posttest narratives (though both subordinate-loaded), differed in content (the story itself), the amount of repetition and predictability, and in their specific vocabulary. The posttest1 story had three repetitions of a situation where a monkey helped another animal who was in trouble, described by a 'because' subordinate which began with an emotion state followed by the cause (the snake was very upset because he had a big knot in his middle). Psychological causes or reasons make up a large majority of children's early adverbial subordinates (MacCabe \& Peterson, 1985; Diessel, 2004, p. 160) therefore this 
may have been a particularly facilitative story for because production. The posttest 2 story contained as many examples of because, but neither in a repetitive situation nor to explain a psychological state. These are tentative suggestions only; further fine-grained research into the subtle effects of story design is required.

Similarly to Kidd (2012), we found considerable variability in response between individual children. For example, in the SUB group, change in the total number of subordinates used between pretest and posttest 1 ranged from a reduction of 5 to an increase of 13 subordinate clauses. We acknowledge that priming may not be the only reason affecting subordinate use but why, in the experimental group, did some children increase their use of subordinates while others did not? It may be that implicit learning via structural priming (at least in our loosely constrained narrative task) has its greatest effect within the zone of proximal development (Vygotsky, 1978) when children are linguistically ready to take that step. We predicted that this would be indexed by scores on BPVS and the CELF Formulated Sentences subtest, the latter a validated assessment of grammatical expression; however a significant correlation was not found for either measure. In this study the variability in responsiveness to priming was not predicted by language abilities. One likely reason for the absence of a significant result is the overall similarity of the children's scores. Our participants' language scores clustered together at the lower end of the typical range and, more importantly, their profiles were also rather homogeneous. The limitation imposed by the relatively small sample size and the small standard deviation on the two language measures must make our preliminary conclusion tentative but we 
propose that factors other than level of language proficiency may determine the likelihood of priming. One obvious factor, which we did not include in the present study, is children's non-verbal reasoning ability, a variable that was a significant predictor in Kidd's (2012) study.

Although parental input is the primary influence in early years, the language environment in school continues to affect children's language competence and use (Huttenlocher, Levine \& Vevea, 1998). Our results reflect the findings of Gamez and Levine (2012) who showed that syntactic complexity of teacher input in whole class activities was associated with growth in children's expressive language skills. In a more specific targeting of particular constructions, our results are also consistent with those of Vasilyeva, Huttenlocher, and Waterfall (2006) who used structural priming in a classroom situation, though we were able to extend the evidence to complex syntax and to demonstrate maintenance of effect over a longer period. Similarly to their experience with passives, our children showed that mastery or choice of subordination was not an all-ornothing skill; the experimental group never reached the point of preferring subordination over coordination of clauses. This is also unsurprising: Geva \& Olsen (1983) stated that everyday spoken speech has little subordination and a high reliance on 'and' to link elements, and Hesketh (2004) found that $63 \%$ of children with language impairment used adverbial subordination in retelling a subordinate-heavy narrative narrative , compared to $74 \%$ using coordination. Nevertheless, considering how small a proportion the experimental input formed of the total language the children were exposed to in the two-week period, it is impressive that the structural priming brought about a significant change in a 
non-constraining narrative assessment. The maintenance of the effect up to 10 weeks later is particularly notable.

\section{Conclusion}

Our study demonstrates that, with typically developing children of moderate language ability, even a small amount of regular exposure to particular grammatical constructions will influence children in their use. Input manipulation over a two-week intervention had a significant effect on children's proportional use of subordination and coordination in multi-clause utterances at post-test1. As in Jaeger and Snider (2013), the changes were small but robust and the effects of this influence were maintained at Post-test2, 10 weeks after the end of the priming phase.

The intervention took place in a whole class setting, showing how priming can be turned to educational use. Our priming of sentences which describe the relationship between events may have encouraged a range of coordinating and subordinating structures, i.e. the facilitation of a generally more complex and explanatory style, appropriate to the education context. It is likely that children's overall language profile, particularly in subordination, did not change; rather that they developed a local expectation of a more complex syntactic style, appropriate for the education setting. In this study, by increasing the use of constructions which children are already in the process of acquiring, priming may have had a two-pronged outcome, affecting language for learning, as well promoting language learning itself. 


\section{Acknowledgments}

This study was funded by a grant awarded by the UK Economic and Social Research Council to the first two authors (RES-000-22-3678). We gratefully acknowledge the staff and children at Greswell Primary and Moss Park Infant School for their enthusiastic collaboration. Thanks also to Paul Conroy, Rachael King and Ruth Wadman for assistance with testing, transcription and preparation of materials.

\section{References}

Bates, D., \& Maechler, M. (2010). Matrix: sparse and dense matrix classes and methods. R package version 0.999375-43, URL http://cran.rproject.org/packages=Matrix

Bencini, G. M. \& Valian, V. V. (2008). Abstract sentence representations in 3-yearolds: Evidence from language production and comprehension. Journal of Memory and Language, 59, 97-113.

Bock, J. K. (1986). Syntactic persistence in language production. Cognitive Psychology, 18, 355-387.

Bock, K. \& Griffin, Z. (2000). The persistence of structural priming: Transient activation or implicit learning? Journal of Experimental Psychology - General, $12,177-92$. 
Branigan, H. P., Pickering, M. J., McLean, J. F. \& Cleland, A. A. (2007). Syntactic alignment and participant role in dialogue. Cognition, 104, 163-197.

Branigan, H. P., McLean, J. F. \& Jones, M. W. (2005). A blue cat or a cat that is blue? Evidence for abstract syntax in young children's noun phrases. In The proceedings of the 29th Annual Boston University Conference on Language Development, (pp. 109-121). Somerville, MA: Cascadilla Press.

Chang, F., Dell, G. S., Bock, K. \& Griffin, Z. M. (2000). Structural priming as implicit learning: A comparison of models of sentence production. Journal of Psycholinguistic Research, 29, 217-230.

Cleland, A. A. \& Pickering, M. J. (2006). Do writing and speaking employ the same syntactic representations? Journal of Memory and Language 54, 185-98.

Crosson, A. C., Lesaux, N. K. \& Martiniello, M. (2008). Factors that influence comprehension of connectives among language minority children from Spanish-speaking backgrounds. Applied Psycholinguistics, 29, 603-625.

Department for Education (2011a) Statistical First Release. http://www.education.gov.uk/rsgateway/DB/SFR/s001012/sfr12-2011.pdf, Department for Education (2011b) The School Curriculum. http://www.education.gov.uk/schools/teachingandlearning/curriculum/pri mary/b00198874/english 
Diessel, H. (2004). The Acquisition of Complex Sentences. Cambridge, UK:

Cambridge University Press

Dunn, L., Dunn, D., Styles, B. \& Sewell, J. (2009). British Picture Vocabulary Scale, 3rd Edition. London, UK: GL Assessment.

Ferreira, V. S. \& Bock, K. (2006). The functions of structural priming. Language and Cognitive Processes, 21, 1011-1029.

Fine, A. B., Jaeger, T. F., Farmer, T. A. \& Qian, T. (2013). Rapid Expectation Adaptation during Syntactic Comprehension. PLoS ONE 8: e77661. doi:10.1371/journal.pone.0077661

Foltz, A., Thiele, K., Kahsnitz, D. \& Stenneken, P. (2015). Children's syntacticpriming magnitude: lexical factors and participant characteristics. Journal of Child Language 42, 932-945.

Gamez, P. \& Levine, S. (2012). Oral language skills of Spanish-speaking English language learners: The impact of high-quality native language exposure. Applied Psycholinguistics, 34, 673-696.

Garraffa, M., Coco, M. I. \& Branigan, H. P. (2015). Effects of Immediate and Cumulative Syntactic Experience in Language Impairment: Evidence from 
Priming of Subject Relatives in Children with SLI. Language Learning and Development, 11, 18-40.

Geva, E. \& Olsen, D. (1983). Children's story re-telling. First Language 4, 85-110.

Gries, S. T. (2005). Syntactic priming: A corpus-based approach. Journal of Psycholinguistic Research, 34, 365-399.

Hesketh, A. (2004). Grammatical performance of children with language disorder on structured elicitation and narrative tasks. Clinical Linguistics and Phonetics, $18,161-182$.

Hoff, E. (2003). The specificity of environmental influence: Socioeconomic status affects early vocabulary development via maternal speech. Child Development, 74, 1368-1378.

Huttenlocher, J., Levine, S. \& Vevea, J. (1998). Environmental input and cognitive growth: A study using time-period comparisons. Child Development, 69, 10121029

Huttenlocher, J., Vasilyeva, M., Cymerman, E. \& Levine, S. (2002). Language input and child syntax. Cognitive Psychology, 45, 337-374. 
Huttenlocher, J., Waterfall, H., Vasilyeva, M., Vevea, J. \& Hedges, L. V. (2010). Sources of variability in children's language growth. Cognitive Psychology, 61, 343-365.

Jaeger, T. F. \& Snider, N. E. (2013). Alignment as a consequence of expectation adaptation: Syntactic priming is affected by the prime's prediction error given both prior and recent experience. Cognition, 127, 57-83.

Kaschak, M. P. (2007). Long-term structural priming affects subsequent patterns of language production. Memory \& Cognition, 35, 925-937.

Kaschak, M. P., Kutta, T. J. \& Schatschneider, C. (2011). Long-term cumulative structural priming persists for (at least) one week. Memory \& Cognition, 39, $381-388$

Kidd, E. (2012). Individual differences in syntactic priming in language acquisition. Applied Psycholinguistics, 33, 393-418.

Klein, H. B., Moses, N. \& Jean-Baptiste, R. (2010). Influence of context on the production of complex sentences by typically developing children. Language, speech, and hearing services in schools, 41, 289-302.

Kutta, T. J. \& Kaschak, M. P. (2012). Changes in task-extrinsic context do not affect the persistence of long-term cumulative structural priming. Acta Psychologica, 141, 408-414. 
Lever, R. \& Sénéchal, M. (2011). Discussing stories: On how a dialogic reading intervention improves kindergartners' oral narrative construction. Journal of experimental child psychology, 108, 1-24.

MacWhinney, B. (2000). The CHILDES Project: Tools for analyzing talk. 3rd Edition. Vol. 2: The Database. Mahwah, NJ: Lawrence Erlbaum Associates.

Marinellie, S. A. (2006). Assessing and facilitating complex sentence formulation in picture description tasks. International Journal of Speech-Language Pathology, 8, 69-78.

McCabe, A. \& Peterson, C. (1985). A naturalistic study of the production of causal connectives by children. Journal of Child Language, 12, 145-159.

Messenger, K., Branigan, H. P. \& McLean, J. F. (2011). Evidence for (shared) abstract structure underlying children's short and full passives. Cognition, 121, 268-274.

Peter, M., Chang, F., Pine, J. M., Blything, R. \& Rowland, C. F. (2015). When and how do children develop knowledge of verb argument structure? Evidence from verb bias effects in a structural priming task. Journal of Memory and Language, 81, 1-15. 
Peterson, C. \& McCabe, M. (1987). The connective 'and': do older children use it less as they learn other connectives? Journal of Child Language, 14, 375-381

Pickering, M. J. \& Branigan, H. P. (1999). Syntactic priming in language production. Trends in Cognitive Sciences, 3, 136-141.

Pickering, M. J. \& Ferreira, V. S. (2008). Structural priming: a critical review. Psychological Bulletin, 134, 427-459.

Reitter, D. \& Moore, J. D. (2014). Alignment and task success in spoken dialogue. Journal of Memory and Language, 76, 29-46.

Rowland, C. F., Chang, F., Ambridge, B., Pine, J. M. \& Lieven, E. V. (2012). The development of abstract syntax: Evidence from structural priming and the lexical boost. Cognition, 125, 49-63.

Ryokai, K., Vaucelle, C. \& Cassell, J. (2003). Virtual peers as partners in storytelling and literacy learning. Journal of Computer Assisted Learning, 19, 195-208.

Savage, C., Lieven, E., Theakston, A. \& Tomasello, M. (2003). Testing the abstractness of children's linguistic representations: Lexical and structural priming of syntactic constructions in young children. Developmental Science, 6, 557-567. 
Savage, C., Lieven, E., Theakston, A. \& Tomasello, M. (2006). Structural priming as implicit learning in language acquisition: The persistence of lexical and structural priming in 4-year-olds. Language Learning and Development, 2, 2749.

Semel, E., Wiig, E. \& Secord, W. (2006). Clinical Evaluation of Language Fundamentals® - 4th edition (CELF® - 4 UK). Oxford, UK: Pearson Assessment.

Serratrice, L., Hesketh, A. \& Ashworth, R. (2015). The use of reported speech in children's narratives: A priming study. First Language, 35, 68-87.

Shimpi, P. M., Gámez, P. B., Huttenlocher, J. \& Vasilyeva, M. (2007). Syntactic priming in 3-and 4-year-old children: Evidence for abstract representations of transitive and dative forms. Developmental Psychology, 43, 1334.

Spooren, W. \& Sanders, T. (2008). The acquisition order of coherence relations: On cognitive complexity in discourse. Journal of Pragmatics, 40, 2003-2026.

Tager-Flusberg, H. (1989). Putting words together: morphology and syntax in the preschool years. In J. B. Gleason (ed) The Development of Language, 2nd Edition, (pp135-165). Columbus, Ohio: Merrill Publishing Company.

Thothathiri, M. \& Snedeker, J. (2008). Syntactic priming during language comprehension in three-and four-year-old children. Journal of Memory and Language, 58, 188-213. 
Vasilyeva, M., Huttenlocher, J. \& Waterfall, H. (2006). Effects of language intervention on syntactic skill levels in preschoolers. Developmental Psychology, 42, 164.

Vasilyeva, M. \& Waterfall, H. (2012). Beyond syntactic priming: Evidence for activation of alternative syntactic structures. Journal of Child Language, 39, 258.

Vasilyeva, M., Waterfall, H. \& Huttenlocher, J. (2008). Emergence of syntax: commonalities and differences across children. Developmental Science, 11(1), 84-97.

Vygotsky, L. S. (1978). Mind in Society. Cambridge, MA: Harvard University Press. 


\section{Appendix A, story examples}

i) Tom and the Bright Red Bicycle - Subordination version

This is a story about a little boy called Tom and the most amazing bicycle in the world. One morning, (1) as Tom and his Mum walked to school, they saw a huge toy shop. Tom was very surprised (2) because he'd never seen it before. He was so excited but Mum said "You have to go to school (3) before you can look in the shop". Tom didn't mind (4) because he liked school but the day seemed to last forever! (5) As soon as the end of school bell rang, Tom jumped up from his desk and ran all the way to the toy shop. (6) When he went inside, he saw the most amazing bicycle in the world! It was brightly coloured and had lightning bolts on the wheels. It was amazing! He wanted it now but it wasn't his birthday for ages! Mum said "You'll have to save up the money (7) before you can buy it". "Oh no", Tom moaned "I'll have to do loads of jobs to afford it (8) because it is so expensive!". "Why don't you ask the neighbours?" suggested Mum.

He was in luck! Their neighbour, Mr Tibbs, had lots of gardening to do and needed Tom's help. First, he gave Tom a ladder and bucket (9) $\underline{\text { because he }}$ $\underline{\text { wanted Tom to pick the apples. Then, Tom got a rake (10) because he needed to }}$ clear up the leaves. Soon, Tom had to stop (11) because it went dark outside. Then, Mr Tibbs gave him some money.

The next day, Tom still really wanted that bicycle (12) so he went to see their other neighbour, Mrs Pooch. She gave him a bucket full of water (13) so that he $\underline{\text { could clean her car. Then she said "My dog Skip, is filthy (14) because he's been }}$ 
playing in the garden. Can you wash him too?" So Tom started washing the dog. (15) When he finished, she thanked him for all his hard work. Then, she gave him some money.

The next day, (16) after school had finished, Tom ran to the toy shop but he was too late. The bicycle had already gone! Tom was so upset! "All that work for nothing" he said to himself. "I really wanted that bicycle!"

(17) When Tom arrived home, his dinner was on the table. But Tom wasn't hungry (18) because he was too upset. He decided to go to bed early. (19) As he walked into his bedroom, he stopped suddenly. There, in the middle of his room, was the bicycle! Mum popped up behind him and said "You really earned it (20) because you worked so hard!" He gave her a huge hug. He took his bicycle outside to play on it for hours. So all that work did pay off in the end! 
ii) Tom and the Bright Red Bicycle - Coordination version

This is a story about a little boy called Tom and the most amazing bicycle in the world. One morning, Tom and his Mum walked to school (1) and they saw a huge toy shop. Tom had never seen it before (2) and was very surprised. He was so excited but Mum said "You have to go to school (3) and you can look in the shop later". Tom liked school (4) and he didn't mind. But the day seemed to last forever! The end of school bell rang (5) and Tom jumped up from his desk. He ran all the way to the toy shop. He went inside (6) and saw the most amazing bicycle in the world! It was brightly coloured and had lightning bolts on the wheels. It was amazing! He wanted it now but it wasn't his birthday for ages! Mum said "You'll have to save up the money (7) and you can buy it another time". "Oh no", Tom moaned "It is so expensive. (8) and I'll have to do loads of jobs to afford it". "Why don't you ask the neighbours?" suggested Mum.

He was in luck! Their neighbour, Mr Tibbs, had lots of gardening to do and needed Tom's help. First, he wanted Tom to pick the apples (9) and he gave Tom a ladder and bucket. Then, Tom needed to clear up the leaves (10) and he got a rake. Soon, it went dark outside (11) and Tom had to stop. Then, Mr Tibbs gave him some money.

The next day, Tom still really wanted that bicycle (12) and he went to see their other neighbour, Mrs Pooch. She gave him a bucket full of water (13) and he cleaned her car. Then she said "My dog Skip has been playing in the garden (14) and he's filthy! Can you wash him too?" Tom started washing the dog. He 
finished (15) and she thanked him for all his hard work. Then, she gave him some money.

The next day, school had finished (16) and Tom ran to the toy shop but he was too late. The bicycle had already gone! Tom was so upset! "All that work for nothing" he said to himself. "I really wanted that bicycle!"

Tom arrived home (17) and his dinner was on the table. But Tom was too upset (18) and he wasn't hungry. He decided to go to bed early. He walked into his bedroom (19) and stopped suddenly. There, in the middle of his room, was the bicycle! Mum popped up behind him and said "You worked so hard (20) and you really earned it!" He gave her a huge hug. He took his bicycle outside to play on it for hours. So all that work did pay off in the end! 


\section{Appendix B, extracts from child narratives (The little monkey's adventure)}

This adaptation of a traditional story, used at post-assessment 1, tells how a monkey goes on a trip and helps out several animals on his way. On his return home he gets into some dangerous situations, and the animals help him out in turn. The extracts given here show a variety of modelled subordinate constructions, including the repetitive 'because' sections which were most likely to elicit subordination in the children's retelling. Examples are taken from two children, one from each group, who produced narratives of similar length and who appeared to have grasped the gist of the story. Attempts at subordination are underlined.

Story I must be back at my tree before the sun goes down.

SUB and and he thought if he should go back when it was sun down

COORD and erm he wanted to he'll get back before erm the sun erm starts to $\underline{\text { rain }}$

Story $\quad$ Along the way, he met a snake. The snake was very upset because he had a big knot in his middle.

SUB er one day, when he went off erm he saw a snake tangled up

COORD and he met a snake yeah, he was upset because erm he had a knot in his .. 
Story Soon, the little monkey heard a lion roaring. The lion was crying because he had a thorn stuck in his paw.

SUB then he heard a roar and and the tiger came out he was roaring because he had a thingy stuck in his toe

COORD he heard a roar and it was a lion was crying and he had a little pin in his paw

Story Further down the road, the little monkey met a pelican. The big bird was crying because she had a hole in her bill. She said "I haven't eaten anything for days now because the fish keep escaping through the hole".

SUB erm the pelican was crying because he had em a hole in his beak when $\underline{\text { he couldn't eat for months because because whenever he eat fish it }}$ keep coming out

COORD and he met a $\ldots$ a pelican. and he had a, and he was crying and he had a hole in his beak and fishes kept going in in his, he kept eating fishes and and they kept going out the hole

Story By the time the little monkey reached the Mountains, the sun was beginning to set. "Oh deary me!" he thought. "It's getting dark now so I'll have to set off home!"

SUB and then he got to the mountain and then it began to go sun down so he decided to go back to his tree 
COORD and then he reached the adventure and he erm he had a look at it but it's it it was just about to rain and then and then it was getting dark and he rushed back to his erm tree

Story When he turned around, he saw the hyena chasing him.

SUB and then er the hyena went to chase him

COORD and then he met a hyena and he and he was going to catch him

Story But suddenly, the rock began to move! It wasn't a rock after all. It was a huge tortoise with a slippery shell. Because the little monkey was so far off the ground, he clung on tightly.

SUB he went to sit on the rock but it moved it wasn't a rock it was big tortoise it just moved when he tried to get off

COORD and then he sat on a rock but the rock moved and then erm there was a big tortoise

Story He slithered in front of the tortoise so that the tortoise had to stop.

SUB the snake stopped so he could carefully get down

COORD then the snake was there and then what did the snake do? he's goes down from the grass or whatever

Story Because it was dark now the little monkey soon got lost. He began to cry

SUB when when it was dark, he lost his way and he began to cry 
COORD and then it was getting dark and he was lost and he began to cry

Story She said "Climb into my bill so that I can carry you home".

SUB and he said if you go in my beak I'll carry you back home

COORD climb jump into my mouth and I'll take you home

Story "Oh thank you" said the little monkey. The bird took him all the way back to his tree.

SUB so he when he got to his tree he said thank you.

COORD he said thank you

and then he took him back to his house and then and he went to sleep

Story That night, as he was going to sleep, he said to himself "What an adventure that was!

SUB (not included in the retelling)

COORD and before he said to himself, it's a good job I went to see the erm the erm the hills 
Table 1. Group comparison (independent samples t-test) for age in months and standard scores of vocabulary (BPVS) and grammar (CELF Formulated Sentences)

\begin{tabular}{llll}
\hline & Condition & Mean (SD) & $p$ \\
\hline Age in & SUB & $71.17(3.13)$ & .37 \\
months & COORD & $70.22(4.02)$ & \\
\hline BPVS & SUB & $90.38(8.08)$ & .73 \\
& COORD & $91.17(7.46)$ & \\
\hline Formulated & SUB & $8.00(2.57)$ & .21 \\
Sentences & COORD & $9.00(2.57)$ & \\
\hline
\end{tabular}

BPVS standard score norm $=100,1 \mathrm{SD}=15$;

CELF standard subtest score norm $=10,1 \mathrm{SD}=3$ 
Table 2: Subordination and coordination use at three time points

\begin{tabular}{|l|l|l|l|l|}
\hline & Group & Pre-intervention & Post1 & Post2 \\
& & Mean (SD) & Mean (SD) & Mean (SD) \\
\hline \multirow{2}{*}{ Examples of } & SUB & $3.54(3.02)$ & $6.29(3.58)$ & $4.71(2.76)$ \\
\cline { 2 - 6 } & COORD & $5.17(3.64)$ & $4.65(3.38)$ & $3.26(2.91)$ \\
\hline \multirow{2}{*}{ coordination } & SUB & $7.83(6.46)$ & $10.25(6.37)$ & $5.29(2.85)$ \\
\hline Proportion of sub & COORD & $8.74(6.02)$ & $14.48(6.43)$ & $7.39(4.34)$ \\
\hline \multirow{2}{*}{ to total sub+coord } & COORD & $.30(.24)$ & $.38(.15)$ & $.46(.20)$ \\
\cline { 2 - 6 } & & $.37(.20)$ & $.23(.12)$ & $.29(.16)$ \\
\hline
\end{tabular}

Note, this table includes all types of subordination and coordination use, not only the primed constructions. 
Figure 1

Number of occurrences of primed conjunctions only, for SUB and COORD groups at all assessment points.

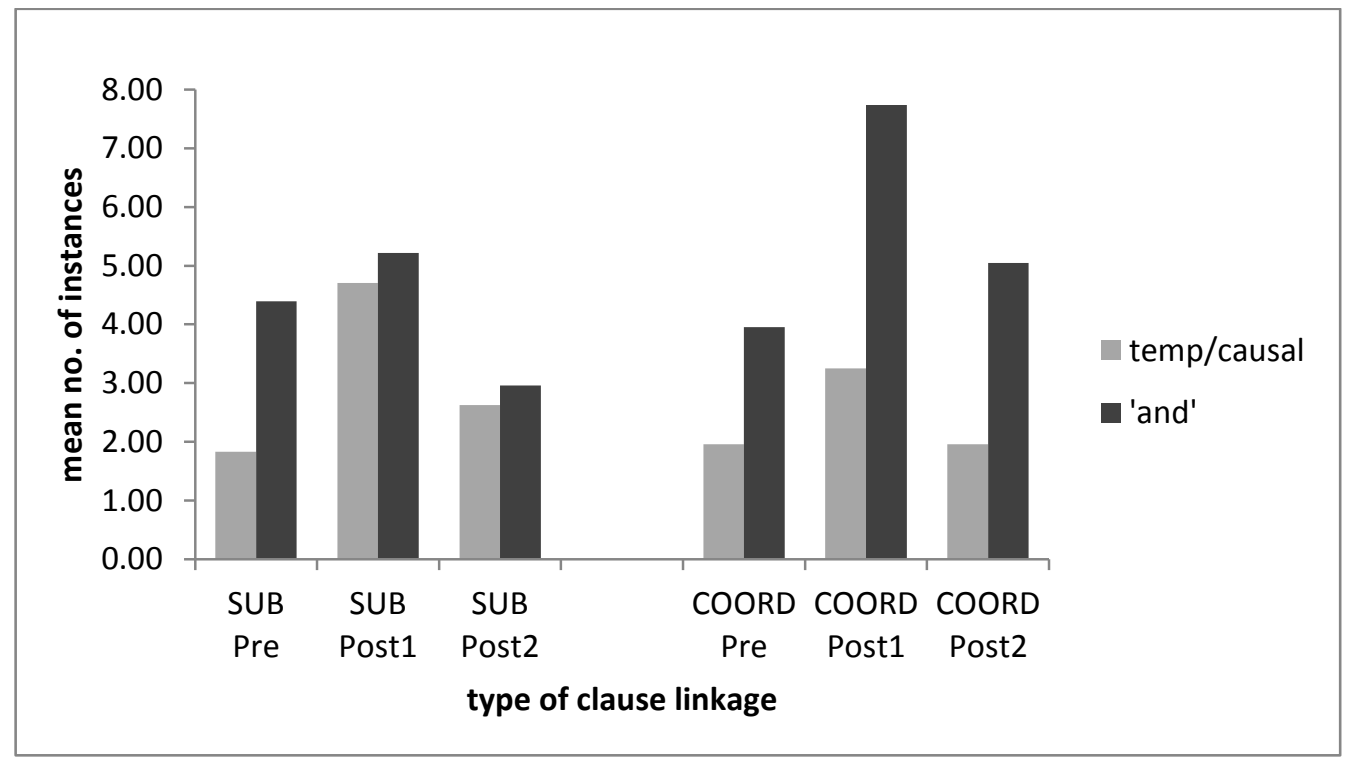

